\title{
Correlation of the score for subjective pain with physical disability, clinical and radiographic scores in recent onset rheumatoid arthritis Piercarlo Sarzi-Puttini*1, Tania Fiorini ${ }^{2}$, Benedetta Panni ${ }^{1}$, Maurizio Turiel ${ }^{2}$, Marco Cazzola ${ }^{1}$ and Fabiola Atzeni ${ }^{1}$
}

\author{
Address: ${ }^{1}$ Rheumatology Unit, University Hospital L. Sacco, Milan, Italy and ${ }^{2}$ Istituto di Scienze Biomediche, Università di Milano, Italy \\ E-mail: Piercarlo Sarzi-Puttini* - sarzi@tiscalinet.it; Tania Fiorini - tania@posta.statfac.unibo.it; Benedetta Panni - benedetta_p@virgilio.it; \\ Maurizio Turiel - maurizio.turiel@unimi.it; Marco Cazzola - marco.cazzola@tiscalinet.it; Fabiola Atzeni - atzenifabiola@hotmail.com \\ ${ }^{*}$ Corresponding author
}

This article is available from: http://www.biomedcentral.com/I47I-2474/3//8

(C) 2002 Sarzi-Puttini et al; licensee BioMed Central Ltd. Verbatim copying and redistribution of this article are permitted in any medium for any purpose, provided this notice is preserved along with the article's original URL.

Keywords: Rheumatoid arthritis, pain, pain measurement

\begin{abstract}
Background: To analyse the relationship between subjective pain score and other measures of clinical, radiographic and functional status; in particular Larsen radiographic scores and Health Assessment Questionnaire (HAQ); in patients with severe rheumatoid arthritis (RA) with a disease duration of less than 3 years.
\end{abstract}

Methods: In this cross sectional study of 105 patients with RA (76 women, 29 men: mean age 50.93; mean disease duration 15.86 months; $71 \%$ rheumatoid factor positive) subjective pain was assessed according to the Visual Analog Scale (VAS). Correlation coefficients between pain score and disease activity measures (patients' global assessment of disease by VAS, number of tender and swollen joints, morning stiffness, erythrocyte sedimentation rate [ESR], C-reactive protein [CRP] and titre of rheumatoid factor, radiographic evaluations (Larsen-Dale scores for radiographic damage of the small joints of the hands, wrist and feet), disability measures (health assessment questionnaire [HAQ]), and demographic variables were calculated; hierarchical regression analysis was done with subjective pain score as the dependent variable.

Results: The Spearman's correlation coefficient comparing subjective pain and HAQ was 0.42 I (P $<0.00 \mathrm{I}$ ), between subjective pain and global assessment of disease and morning stiffness was 0.573 $(\mathrm{p}<0.00 \mathrm{I})$ and $0.427(\mathrm{P}<0.00 \mathrm{I})$ respectively, and between pain and number of tender and swollen joints 0.037 and 0.050 respectively $(p>0.05)$. In regression analysis, global assessment of disease by patients explained $32.8 \%$ of the variation in pain intensity score, morning stiffness $10.7 \%$, CRP 4.0\%, HAQ 3.8\% and Larsen-Dale scores explained $2.1 \%$; other variables were not significant in the model.

Conclusions: Pain scores of patients with early severe rheumatoid arthritis are correlated at higher levels with patients' global assessment of disease and with morning stiffness rather than with radiographic or other clinical variables such as number of tender and swollen joints. 


\section{Introduction}

Pain is one of the major complaints of patients suffering from rheumatoid arthritis [1]. It is almost always present and it is the main reason for medical consultation [2]. Moreover, in the early stages of the disease, pain reflects the nociceptive effects of local inflammation and is often a prominent and persistent feature. However, pain is a personal subjective experience that varies quite dramatically among individuals in response to an apparently similar stimulus.

In patients with chronic rheumatic diseases, such as RA, several methods for a quantitative assessment of pain can be used [3-7]; the most simple and reliable is the evaluation of subjective pain by visual analog scale $(0-100 \mathrm{~mm})$ [3]. This parameter is also included in the set of parameters to evaluate the American College of Rheumatology (ACR) improvement criteria of the disease [8].

Analyses of correlation between subjective pain score and the radiographic scores, clinical, psychological and functional parameters may differ according to the severity and the disease duration. Moreover, most of the studies are referred to RA patients with a disease duration of at least several years [9-16].

The aim of this cross sectional study was to evaluate the correlation between subjective pain score and the other clinical, radiographic and functional parameters or scores commonly used in early severe RA patients; in particular, to examine whether other variables might provide greater explanation of the variation in subjective pain score in these patients.

\section{Patients and Methods}

A total of 105 patients with a diagnosis of Rheumatoid Arthritis (RA) (according to the American College of Rheumatology criteria of 1987) [17] who were to be enrolled in a prospective trial comparing the effectiveness of several treatment strategies, were included in this study.

All patients has a disease duration of less than 3 years, were older than 16 years, and were free from any other serious disease process. Demographic and clinical characteristic and treatment of the study patients are reported in table 1 .

None of these patients had been previously treated with disease modifying antirheumatic drugs (DMARDs). A total of $50.5 \%$ patients were already treated with prednisone (median dosage $5 \mathrm{mg} /$ day).

Pain was assessed according to a $100-\mathrm{mm}$ horizontal visual analog scale (VAS) $(0=$ no pain and $100=$ most severe pain). The patients' functional disability index was as-
Table I: Demographic and clinical characteristics and treatment of the study patients

\begin{tabular}{lc}
\hline $\mathbf{N}^{\circ}$ of patients & 105 \\
\hline & \\
Age, years & $50.93 \pm 10.72$ \\
Female / Males & $76 / 29$ \\
Disease duration, months & $15.86 \pm 8.14$ \\
RA test + / - & $71 / 34$ \\
Severity of pain (VAS mm) & $61.65 \pm 19.10$ \\
Duration of morning stiffness (min) & $82.14 \pm 49.45$ \\
Swollen joints (no.) & $11.00 \pm 5.83$ \\
Tender joints (no.) & $14.24 \pm 6.75$ \\
HAQ (0-3) & $1.39 \pm 0.59$ \\
Assessment of patients' disease activity & $50.84 \pm 21.03$ \\
(VAS mm) & \\
ESR (mm/lh) & $48.78 \pm 20.00$ \\
CRP (mg/dl) & $3.06 \pm 1.97$ \\
Larsen-Dale score (0-200) & $15.90 \pm 13.97$ \\
Concomitant use of: & \\
- NSAIDS, \% of patients & $70.9 \%$ \\
- Systemic corticosteroids, \% of patients & $50.5 \%$ \\
\end{tabular}

VAS: Visual Analogue Scale; ESR: Erythrocyte Sedimentation Rate; CRP: C Reactive Protein. HAQ: Health Assessment Questionnaire

sessed according to Stanford Health Assessment Questionnaire (HAQ); the overall index reported here varies from 0 to 3, 0 being the best (no problem) and 3 being the worst score [18]. Other clinical variables included: number of tender and swollen joints (66/68 joints), duration of morning stiffness, patients' general health assessed according to a 100-mm VAS; laboratory evaluation included erythrocyte sedimentation rate (ESR), C-reactive protein (CRP) and the titre of rheumatoid factor.

Radiographic damage of the small joints was assessed according to Larsen-Dale score, ranging from 0-200 points [19].

Bivariate relations between pain score and disease activity, functional status and demographic variables were analyzed by calculating Spearman's correlation coefficient. Regression analysis was performed with pain score (VAS) as the dependent variable; independent variables included age, sex, serologic status (positive/negative), duration of disease, patients global assessment of disease, number of tender and swollen joints, morning stiffness, LarsenDale radiographic score, ESR and CRP. All statistical analyses were done with the SPSS/PC+ statistical package. P values less than 0.05 were considered statistically significant. 


\section{Results}

\section{Patients' characteristics}

The 105 patients had a mean duration of disease of 15.8 months (SD 8.14); the mean age of patients was 50.9 (SD 10.7). Table 1 further shows that 76 (67\%) were female, and $71(60 \%)$ of the study population was positive for rheumatoid factor.

Disease activity measure show this patient group to have rather active disease. Disability score (HAQ) indicate that functional capacity was significantly affected in this group of patients.

\section{Bivariate correlations}

Subjective pain score was correlated statistically significantly with ESR $(r=0.375, p<0.001)$. CRP $(r=0.296, p$ $<0.001)$, HAQ $(\mathrm{r}=0.421, \mathrm{p}<0.001)$, global assessment of disease activity by patients $(\mathrm{r}=0.573$, $\mathrm{p}<0.001)$, morning stiffness $(r=0.427, \mathrm{p}<0.001)$.

No significant statistical correlation was observed between subjective pain scores and rheumatoid factor values $(\mathrm{r}=0.068, \mathrm{p}=0.255)$, neither between pain scores and number of swollen $(\mathrm{r}=0.050, \mathrm{p}=0.314)$ and tender joints $(r=0.037, p=0.359)$, Larsen radiographic score $(r$ $=0.055, \mathrm{p}=0.284)$, age $(\mathrm{r}=0.040, \mathrm{p}=0.320)$, and disease duration $(\mathrm{r}=0.074, \mathrm{p}=0.210)$.

\section{Multiple linear regression analysis}

In the multiple regression analysis (forward selection), the global assessment of disease by patients was the primary explanatory variable for the pain subjective score, accounting for $32.8 \%$ of the variation. Morning stiffness contributed only $10.7 \%$ to explaining the variation of the subjective pain score, CRP, HAQ and Larsen-Dale score contributed $4.0 \%, 3.8 \%$ and $2.1 \%$ respectively (Table 2 ).

Table 2: Explanatory variables for findings on subjective pain score, by multiple linear regression analysis $(n=105)$

\begin{tabular}{lcccc}
\hline & \multicolumn{4}{c}{ Explanation } \\
\cline { 2 - 5 } \multicolumn{1}{c}{ Variable } & B & SE & $\begin{array}{c}\text { Rate } \\
\text { (\%) }\end{array}$ & $P$ \\
& & & & \\
\hline Global assessment of dis- & 0.330 & 0.074 & 32.8 & 0.000 \\
ease by patients & & & & \\
Morning stiffness & 0.119 & 0.29 & 10.7 & 0.000 \\
CRP & 2.225 & 0.71 & 4.0 & 0.009 \\
HAQ & 6.472 & 2.506 & 3.8 & 0.010 \\
Larsen-Dale score & 0.203 & 0.101 & 2.1 & 0.048 \\
Total & & & 53.3 & \\
& & & &
\end{tabular}

B: coefficient; SE: standard error.

\section{Discussion}

In this present study, the primary observation is that subjective pain intensity (VAS) in early severe RA patients is significantly correlated with patients' global health assessment, HAQ and laboratory parameters (ESR, CRP). Moreover, we observed a very strong correlation between pain and the duration of morning stiffness but no significant correlation with other common clinical variables used for RA patients evaluation such as number of swollen and tender joints, rheumatoid factor, or demographic variables such as age, sex or disease duration.

The HAQ has been shown to be valid and reliable for the assessment of functional status in patients with RA, and it is the best variable for predicting work disability and mortality [20,21]. Health global assessment by physician and patients are important clinical variables included in the ACR set criteria for evaluating disease improvement [9].

In the regression model, $53.3 \%$ of the variation of the subjective pain scores was explained by Health global assessment by patients, HAQ score, morning stiffness, CRP and Larsen-Dale radiographic score, while sex, age, and duration of disease, ESR and rheumatoid factor did not contribute statistically significantly to the model.

It is likely that the lack of significance of certain variables in this model may be correlated with the duration and severity of the disease; on the other hand, patients global assessment of the disease and HAQ score are definitely influenced by motivational and psychological factors $[22,23]$. In this study, however, psychological factors have not been assessed but they may explain part of the variance in subjective pain [24-26].

It has been suggested that anatomical damage of joints leads to functional declines in long-standing RA; this could be the reason why Larsen-Dale score poorly correlates with pain in early RA [27-30].

It is possible that dissociation between pain and clinical scores may reflect a relative preservation of joints and correlation may be higher with more extensive and permanent anatomical damage [31-33].

In conclusion our results confirm that subjective pain score is strongly associated with disability and health assessment indexes. These findings suggest that pain, at least in the early stage of the disease, reflects more the functional disability of the patients than the clinical extent or the early radiographic damage of the disease.

\section{References}

I. La Montagna G, Tirri R, Baruffo A, Preto B, Viaggi S: Clinical pattern of pain in rheumatoid arthritis. Clin Exp Rheum 1997, I 5:48I-485 
2. Kazis LE, Meenan RF, Anderson J]: Pain in the rheumatic disease. Arthritis Rheum 1983, 26:1017-1022

3. Bird HA, Dixon JS: The measurement of pain. Baillieres Clin Rheumatol | 987, I:7|-89

4. Grossi E, Borghi C, Cerchiari EL, Della Puppa T, Francucci B: Analogue chromatic continuous scale (ACCS): a new method for pain assessment. Clin Exp Rheumatol 1983, I:337-340

5. Melzack R: The McGill Pain questionnaire: major properties and scoring methods. Pain 1985, 21:85-92

6. Melzack R, Katz J, Jeans ME: The role of compensation in chronic pain: Analysis using a new method of scoring the McGill Pain Questionnaire. Pain 1985, 23:101-1 I2

7. Maiani G, Sanavio E: Semantics of pain in Italy: the Italian version of the McGill Pain Questionnaire. Pain 1985, 22:399-405

8. Felson DT, Andersen J], Boers M, et al: American College of Rheumatology preliminary definition of improvement in rheumatoid arthritis. Arthritis Rheum 1995, 38:727-735

9. Cavalieri F, Salaffi F, Ferraccioli GF: Relationship between physical impairment, psychological variables and pain in rheumatoid disability. An analysis of their relative impact. Clin Exp Rheumatol I991, 9:47-50

10. Guillemin F, Briancon S, Pourel J: Functional disability in rheumatoid arthritis: two different models in early and established disease. J Rheumatol 1992, 19:366-369

II. Pincus T, Callahan L, Brooks RH, Fuchs HA, Olsen NJ, Kaye J]: Selfreport questionnaire scores in rheumatoid arthritis compared with traditional physical, radiographic and laboratory measures. Ann Intern Med 1989, I I 0:259-266

12. Hakala M, Nieminem P, Manelius J: Joint impairment is strongly correlated with disability measured by self-report questionnaires: functional status assessment of individuals with rheumatoid arthritis in a population based series.J Rheumatol 1994, 21:64-69

13. Kaarela K, Sarna S: Correlations between clinical facets of outcome in rheumatoid arthritis. Clin Exp Rheumatol 1993, I I:643644

14. Möttönen T, Paimela L, Leirisalo-Repo M, Kautiainen H, Ilonen J, Hannonen $\mathrm{P}$ : Only high disease activity and positive rheumatoid factor indicate poor prognosis in patients with early rheumatoid arthritis treated with "sawtooth" strategy. Ann Rheum Dis 1998, 57:533-539

15. Sokka T, Kankainen A, Hannonen P: Scores for functional disability in patients with rheumatoid arthritis are correlated at higher levels with pain scores than with radiographic scores. Arthritis Rheum 2000, 43:386-389

16. Van Leeuwen MA, van der Heijde DMFM, van rijswijk MH, Houtman PM, van Riel PLCM, van de Putte LBA, et al: Interrelationship of outcome measures and process variables in early rheumatoid arthritis: a comparison of radiologic damage, physical disability, joint counts and acute phase reactants. J Rheumatol 1994, 2 1:425-429

17. Arnett FC, Edworthy SM, Block DA, et al: The American Rheumatism Association 1987 revised criteria for the classification of rheumatoid arthritis. Arthritis Rheum 1988, 3 1:315-324

18. Fries JF, Spitz PW, Young DY: The dimensions of health outcomes: The Health Assessment Questionnaire, disability and pain scales. J Rheumatol I 982, 9:789-793

19. Larsen A, Thoen J: Hand radiography of $\mathbf{2 0 0}$ patients with rheumatoid arthritis repeated after an interval of one year. Scand J Rheumatol 1987, 16:395-40 |

20. Sokka $T$, Kautiainen $H$, Möttönen $T$, Hannonen P: Work disability in rheumatoid arthritis 10 years after the diagnosis. J Rheumatol 1999, 26:168I-1685

21. Pincus T, Callahan L: Quantitative measures to assess, monitor and predict morbidity and mortality in rheumatoid arthritis. Baillieres Clin Rheumatol 1992, 6:161-191

22. Van der Heide A, Jacobs JWG, Haanen HCM, Bijlsma JWI: Is it possible to predict the first year extent of pain and disability for patients with rheumatoid arthritis? J Reumatol 1995, 22: 14661470

23. Van der Heide A, Jocobs JWG, Grietje A, et al: Physical disability and psychological well being in recent onset rheumatoid arthritis. J Rheumatol 1 994, 2 1:28-32

24. Evers AWM, Kraaimaat FW, Geenen R, Bijlsma JWJ: Determinants of psychological distress and its course in the first year diag- nosis in rheumatoid arthritis patients. I Behav Med 1997 20:489-504

25. Evers AWM, Taal E, Kraaimaat FW, et al: A comparison of two recently developed health status instruments for patients with arthritis: Dutch-AIMS 2 and IGRL. Br J Rheumatol 1998, 37:157164

26. Bijlsma JW, Huiskes CJ, Kraamaat FW, Vanderveen MJ, Huber-Bruning O: Relation between patients' own health assessment and clinical and laboratory findings in rheumatoid arthritis. J Rheumatol | 99|, | 8:650-3

27. Regan-Smith MG, O'Connor GT, Kwoh CK, Brown LA, Olmstead EM, Burnett JB: Lack of correlation between the Steinbrocker staging of hand radiographs and the functional health status of individuals with rheumatoid arthritis. Arthritis Rheum 1989, 32:128-133

28. Fex E, Jonsson K, Johnson U, Eberhardt K: Development of radiographic damage during the first 5-6 years of rheumatoid arthritis: a prospective follow-up study of a Swedish cohort. $\mathrm{Br}$ J Rheumatol 1996, 35: I 106-1II5

29. Wolfe F, Sharp JT: Radiographic outcome of recent-onset rheumatoid arthritis: a 19-year study of radiographic progression. Arthritis Rheum 1998, 4I:157|-1582

30. Fries JF: Re-evaluating the therapeutic approach to rheumatoid arthritis: the "sawtooth" strategy.J Rheumatol 1990, 22:1215

31. Van der Heijde DMFM, van't Hof MA, van Riel PLCM, van Leeuwen $M A$, van Rijswijk MH, van de Putte LBA: A comparison of validity of single variables and composed indices for measuring disease activity in rheumatoid arthritis. Ann Rheum Dis 1992 51:177-18I

32. Prevoo MLL, van't Hof MA, Kuper HH, van Leeuwen MA, van de Putte LBA, van Riel PLCM: Modified disease activity scores that include twenty-eight-joint counts: development and validation in a prospective longitudinal study of patients with rheumatoid arthritis. Arthritis Rheum 1995, 38:44-48

33. Kirwan JR: Conceptual issues in scoring radiographic progression in rheumatoid arthritis. J Reumatol 1999, 26:720-725

\section{Pre-publication history}

The pre-publication history for this paper can be accessed here:

http://www.biomedcentral.com/1471-2474/3/18/prepub
Publish with BioMed Central and every scientist can read your work free of charge

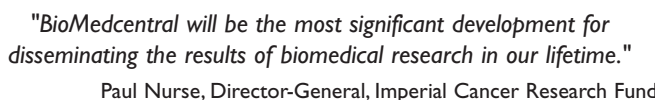

Publish with BMC and your research papers will be:

- available free of charge to the entire biomedical community

- peer reviewed and published immediately upon acceptance

- cited in PubMed and archived on PubMed Central

- yours - you keep the copyright

Submit your manuscript here:

http://www.biomedcentral.com/manuscript/
BioMedcentral.com editorial@biomedcentral.com 